\title{
Estudo da Densidade de Ligações Cruzadas em Géis Superabsorventes Obtidos do Acetato de Celulose
}

\author{
André M. Senna, Aparecido J. de Menezes, Vagner R. Botaro \\ Departamento de Ciências dos Materiais, UFSCar
}

\begin{abstract}
Resumo: Neste trabalho foram realizadas sínteses de géis derivados de acetato de celulose (AC) com grau de substituição (GS) 2,5 por intermédio de reações de reticulação via esterificação. Os grupos hidroxílicos livres do AC foram reagidos com o dianidrido do ácido 1,2, 4, 5 benzenotetracarboxílico (PMDA) em meio homogêneo. As caracterizações foram realizadas por TGA (Análise termogravimétrica), espectroscopia na região do infravermelho (FTIR), retro titulação para determinar o grau de substituição do AC e microscopia de força atômica (AFM). Os géis foram sintetizados com as seguintes razões estequiométricas: [1:1], [1:2/3], [1:3] e [3:1] mol de PMDA/mol de $\mathrm{OH}$ livre respectivamente. A base da teoria de Flory-Rehner foi empregada para determinar ligações cruzadas nos géis. Os resultados de AFM mostram topografias distintas quando são comparados os géis entre si e quando os géis são comparados ao polímero de acetato de celulose. Este trabalho foi motivado pela importância tecnológica de polímeros de fontes renováveis como a celulose, em que um derivado de celulose foi usado para obter um polímero promissor para liberação controlada de medicamentos e adsorção de metais pesados em meio aquoso. Uma das vantagens deste polímero derivado do acetato de celulose é o emprego de poucas etapas na sua síntese.
\end{abstract}

Palavras-chave: Gel, ligações cruzadas, acetato de celulose.

\section{Study of the Crosslinking Density in Superabsorbent Gels Obtained from Cellulose Acetate}

\begin{abstract}
This work reports the synthesis of gels derived from cellulose acetate (CA) with degree of substitution (DS) 2.5 through esterification and crosslinking reactions. The free hydroxyl groups were reacted by using dianhydride of acid 1,2,4,5 benzenotetracarboxylic (PMDA) as modifier in a homogeneous media. Characterization was performed with Thermogravimetric Analysis (TGA), Fourier Transform Infrared Spectroscopy (FTIR), retrotitration (known as back titration) to determine the degree of substitution of AC and atomic force microscopy (AFM). The gels were synthesized with the following stoichiometric ratios: [1:1], [1:2/3], [1:3] and [3:1] PMDA mol/mol of free OH, respectively. A gel was synthesized in excess of $200 \%$ of PMDA in relation to free OH groups of the AC. The basis of the Flory-Rehner theory was used for determining crosslinking in the gels. Briefly, the main results showed that the crosslinking density increased proportionally to the amount of PMDA added to the reaction medium. Distinct AFM topographies were obtained for distinct gels, which were also different from the polymer cellulose acetate. This work was motivated by the technological importance of polymers from renewable sources such as cellulose, in which a cellulose derivative was developed with promising application in drug delivery and in adsorption of heavy metals in aqueous systems. The advantage of this cellulose acetate derivative is the use of fewer steps in its synthesis.
\end{abstract}

Keywords: Gel, crosslink, cellulose acetate.

\section{Introdução}

Os primeiros derivados de celulose sintetizados em laboratório e produzidos em escala industrial foram os ésteres de celulose de ácidos orgânicos e inorgânicos. Esses ésteres se formam quando os grupos hidroxilas das cadeias de celulose são substituídos por grupos acila. A diminuição da quantidade de grupos $\mathrm{OH}$ na cadeia de celulose leva a formação de produtos normalmente mais solúveis do que a celulose, uma vez que os derivados são materiais menos cristalinos devido à diminuição da extensão de ligações de hidrogênio intra e intermoleculares.

Os ésteres de celulose mais importantes produzidos industrialmente são acetato de celulose (CA), propionato acetato de celulose (CAP) e butirato acetato de celulose (CAB). Esses ésteres de celulose mesmo sendo, normalmente, mais caros que termoplásticos originados de petróleo, são produzidos em grande escala por causa de suas excelentes propriedades. Tanto a natureza do grupo substituinte quanto a extensão em que os grupos hidroxilas são substituídos, levam o derivado a apresentar diferentes propriedades térmicas, mecânicas, físicas e químicas. Os valores do grau de substituição podem variar desde próximos a zero até o valor máximo de substituição $0^{[1-3]}$. Ésteres de celulose são empregados na fabricação de fibras têxteis, materiais plásticos, filmes, blendas poliméricas, cápsulas para a indústria farmacêutica, filtros de cigarro, reforço em materiais compósitos, etc. . O acetato de celulose (AC) é um polímero de grande importância industrial e sua principal utilidade inclui fios para a indústria têxtil, filtros, filmes fotográficos transparentes e pigmentados.

No presente trabalho e em outros já realizados pelo grupo, o AC tem sido empregado na síntese de géis superabsorventes a partir de reações de entrecruzamento com dianidridos ${ }^{[4]}$. Essas reações, mas especificamente de esterificação, são realizadas em meio homogêneo onde a densidade de ligações cruzadas entre as cadeias de AC é controlada pela quantidade do agente de entrecruzamento empregado na síntese. Géis são materiais onde cadeias poliméricas formam redes poliméricas. As cadeias poliméricas são interligadas através de ligações cruzadas em nível microscópico por ligações químicas ${ }^{[5]}$.

O grau de intumescimento dos géis depende da densidade de ligações cruzadas, isto é, do grau de fechamento do retículo, e constitui a base de um método experimental para a determinação do tamanho médio dos segmentos entre os pontos de cruzamento de cadeias, o chamado Mc. A relação de Flory-Rehner é uma das mais empregadas em estudos dessa natureza e origina-se da 
combinação da teoria de Flory-Huggins para misturas polímerosolvente com a teoria da mecânica estatística para a variação da energia livre provocada pelo intumescimento. Os parâmetros de solubilidade $(\delta)$ e de interação polímero - solvente $(\chi)$ são variáveis termodinâmicas de especial interesse na caracterização de sistemas poliméricos tendo em vista que o seu conhecimento permite a determinação da densidade de ligações cruzadas (v) em redes poliméricas simples ou interpenetrantes ${ }^{[6]}$.

A teoria de Flory-Rehner relaciona a densidade de ligações cruzadas com o intumescimento $(\% \mathrm{~S})$, pois, quanto menor a densidade de ligações cruzadas, maior será o \%S. Isso ocorre devido o afastamento das cadeias poliméricas, quanto menor for a quantidade de ligações cruzadas em uma rede polimérica, mais as cadeias poliméricas poderão afastar-se uma das outras ${ }^{[4]}$. Conseqüentemente a quantidade de solvente entre as cadeias poliméricas será maior, como está ilustrado na Figura 1.

Foi possível obter um material altamente entrecruzado a partir da utilização de excesso de agente reticulante, provocando o deslocamento do equilíbrio da reação para a formação de produtos, de acordo com a teoria de Le Chatelier.

\section{Material e Métodos}

\section{Síntese dos géis}

\section{Matéria prima}

Para a reação de obtenção dos géis foi usado o acetato de celulose fornecido pelo grupo RHODIA ${ }^{\circledR}$, utilizado comercialmente como matéria prima para produzir filtros de cigarro, com grau de substituição (GS) 2,5.

O dianidrido PMDA (dianidrido do ácido 1,2,4,5 benzenotetracarboxílico), utilizado com agente de entrecruzamento, foi fornecido pela SIGMA-ALDRICH ${ }^{\circledR}$ com pureza maior ou igual a $75 \%$. O solvente foi a acetona (propanona) com pureza de no mínimo 99\% e o catalisador foi a trietilamina com pureza mínima de $99 \%$.

Uma amostra de acetato de celulose, fornecido pela SIGMAALDRICH $^{\circledR}$, com $39,7 \%$ em massa de acetil e com massa molar média (MM) igual a 50.000 g.mol ${ }^{-1}$ foi usado como padrão para as análises de determinação do grau de substituição (GS).

\section{Purificação dos reagentes}

O AC foi imerso em éter etílico por 30 minutos, em etanol por 1 hora e em seguida lavado com água destilada. Posteriormente, foi submerso em água destilada com temperatura de $80{ }^{\circ} \mathrm{C}$ durante 3 horas e em seguida seco em estufa a vácuo a $80{ }^{\circ} \mathrm{C}$ durante 24 horas. O PMDA foi colocado em a estufa sob vácuo de $625 \mathrm{mmHg}$ a temperatura de $210{ }^{\circ} \mathrm{C}$ durante duas horas para eliminar possíveis hidratações no dianidrido.

\section{Determinação do grau de substituição do acetato de celulose (GS)}

$0,5 \mathrm{~g}$ de $\mathrm{AC}$ seco em estufa por 1 hora a $80{ }^{\circ} \mathrm{C}$ foi adicionado a uma mistura de etanol/água 75:25 v/v e aquecido por 30 minutos a $60{ }^{\circ} \mathrm{C}$. Após o aquecimento, foram adicionados $25 \mathrm{~mL}$ de solução de $\mathrm{NaOH}(0,5 \mathrm{M})$, previamente padronizada. O meio reacional foi aquecido novamente por 15 minutos a $60{ }^{\circ} \mathrm{C}$ e em seguida reagiu-se por 72 horas à temperatura ambiente. $\mathrm{O}$ excesso de $\mathrm{NaOH}$ foi titulado com solução padronizada de $\mathrm{HCl}(0,5 \mathrm{M})$, utilizando-se fenolftaleina como indicador.

O mesmo procedimento descrito acima foi realizado utilizando-se $0,500 \mathrm{~g}$ de papel filtro Whatman $\mathrm{N}^{\mathrm{o}} 1$ finamente dividido e seco em estufa por 1hora a $50{ }^{\circ} \mathrm{C}$. Esse meio reacional serviu como branco para os cálculos do grau de substituição (GS).

O GS foi calculado usando a seguinte equação:

$$
\begin{aligned}
\% \text { Acetil } & =\frac{\left\{\left[\left(\mathrm{V}_{\mathrm{NaOH}} \mathrm{XA}\right)-\left(\mathrm{V}_{\mathrm{HCI}} \mathrm{XB}\right)\right]-\left[\left(\mathrm{V}_{\mathrm{NaOH}} \mathrm{XA}\right)-\left(\mathrm{V}_{\mathrm{HCI}} \mathrm{XB}\right)\right]\right\} \times 4,3}{\mathrm{~m}} \\
\mathrm{GS} & =\frac{3,86 \times(\% \text { Acetil })}{102,4-(\% \text { Acetil })}
\end{aligned}
$$

onde: \%Acetil é a porcentagem de grupos acetil na amostra, A é a concentração da solução de $\mathrm{NaOH}$ em $\mathrm{mol} / \mathrm{L}$; B é a concentração da solução de $\mathrm{HCl}$ em mol.L ${ }^{-1}$; $\mathrm{VNaOH}$ e V'NaOH são os volumes da solução de hidróxido adicionados nas amostras e no branco, respectivamente, $\mathrm{VHCl}$ e V' $\mathrm{HCl}$ são os volumes de $\mathrm{HCl}$ adicionados nas amostras e no branco respectivamente e m é a massa da amostra em $\operatorname{gramas}^{[7]}$. A determinação do grau de substituição foi feita em triplicata .

\section{Procedimento de síntese dos géis}

A reação foi realizada em meio homogêneo, à temperatura ambiente e sob forte agitação magnética. $\mathrm{O}$ emprego de um meio reacional completamente anidro foi fundamental para o sucesso da reação. O AC foi dissolvido em acetona (propanona) na proporção de $10 \% \mathrm{~m} / \mathrm{v}$. Após a completa dissolução do polímero, o PMDA foi adicionado ao meio reacional, seguido do catalisador trietilamina. Os géis foram sintetizados com as seguintes razões estequiométricas: 1:1 (GR1:1); 1: 2/3 (GR1:2/3), 1:3 e GR3:1) mol de PMDA/mol de $\mathrm{OH}$ livre respectivamente. Quando o sistema demonstrou visualmente a formação do gel, ocorreu um aumento repentino de viscosidade. Nesse momento, o gel foi transferido para uma placa de Petri e levado a estufa com temperatura de $60^{\circ} \mathrm{C}$, onde permaneceu até as amostras apresentarem massas constantes. Após a secagem, o gel foi submerso em solução de etanol/água a $80 \%$ v/v respectivamente até que não fossem mais identificados

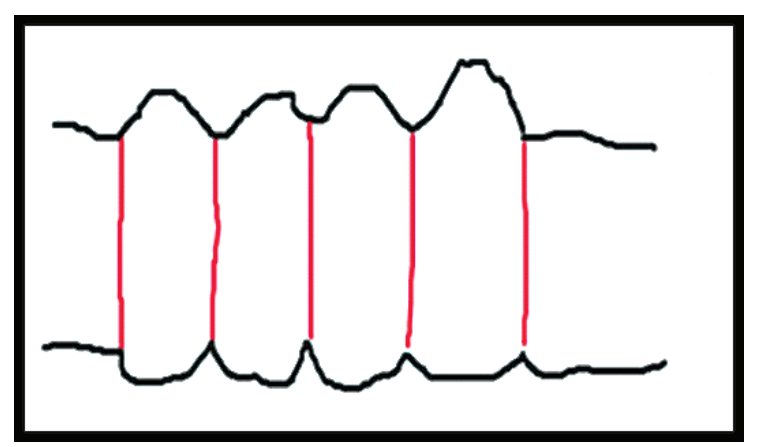

(a)

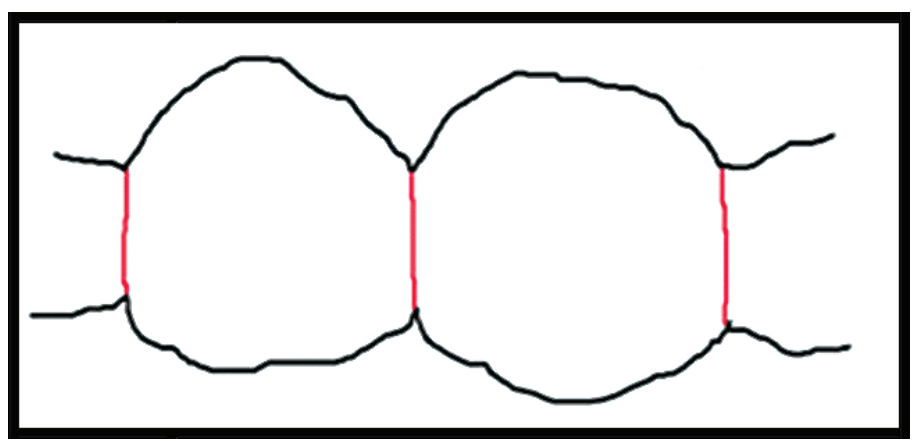

(b)

Figura 1. a) Representa um polímero termorrígido com alta densidade de ligações cruzadas; b) Representa um polímero termorrígido com baixa densidade de ligações cruzadas. 
grupos aromáticos por espectrofotometria na região do ultravioleta. Posteriormente, os géis foram lavados com água destilada durante 10 dias à temperatura ambiente e posteriormente secos em estufa a vácuo a $60^{\circ} \mathrm{C}$ até massa constante.

\section{Análises dos géis}

Os espectros de FTIR foram obtidos pelo método de pastilhas de $\mathrm{KBr}$. As análises termogravimétricas (TGA e DTG) foram realizadas em atmosfera de nitrogênio com rampa de aquecimento $20^{\circ} \mathrm{C} /$ min e temperatura máxima de $900{ }^{\circ} \mathrm{C}$, partindo da ambiente.

\section{Determinação da densidade de ligações cruzadas}

Corpos de prova com massa de aproximadamente $0,400 \mathrm{~g}$ e com formato cilíndrico foram cortados e em seguida mergulhados em solventes com diferentes parâmetros de Hildebrand (tabela 1)

Os corpos de prova permaneceram submersos dentro de tubos Falcon de $50 \mathrm{~mL}$ na ausência total de luz até atingir o equilíbrio. De

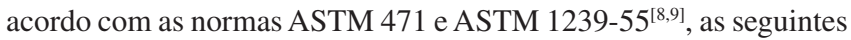
expressões foram empregadas para os cálculos e intumescimento e ligações cruzadas (Equações 2-4):

$$
\mathrm{S} \%=\left[\left(\mathrm{W}-\mathrm{W}_{\mathrm{o}}\right) / \mathrm{W}_{0}\right] \times 100
$$

Sendo $\mathrm{S} \%$ o intumescimento no equilíbrio; $\mathrm{W}_{\mathrm{o}}$ a massa inicial do corpo de prova e $\mathrm{W}$ a massa final. O grau de intumescimento no equilíbrio expresso pelo parâmetro Q é também chamado de coeficiente de intumescimento no equilíbrio e é determinado experimentalmente pela relação:

$$
\mathrm{Q}=\left(\mathrm{m}-\mathrm{m}_{\mathrm{o}}\right) / \mathrm{m}_{\mathrm{o}} \times \rho
$$

Na qual $m_{o}$ é a massa do polímero seco, $m$ a massa do polímero inchado e $\rho$ a densidade do solvente. Após a obtenção dos dados experimentais foi possível determinar a densidade de ligações cruzadas nos hidrogéis aplicando-se a Equação 4:

$$
v=-\left[\ln \left(1-\mathrm{V}_{\mathrm{r}}\right)+\mathrm{V}_{\mathrm{r}}+\chi \mathrm{V}_{\mathrm{r}}^{2}\right] / \rho \mathrm{V}_{1}\left(\mathrm{~V}_{\mathrm{r}}^{1 / 3}-\mathrm{V}_{\mathrm{r}} / 2\right)
$$

Onde $\mathrm{V}_{\mathrm{r}}$ é o volume reduzido; $\mathrm{V}_{1}$ é o volume molar do solvente puro e $\chi$ interação polímero-solvente.

\section{Preparação de filmes poliméricos para obtenção de imagem de AFM}

A preparação dos filmes de hidrogéis necessitou de desenvolvimento de uma técnica especial, visto que os hidrogéis são polímeros termorrígidos, insolúveis e não fundem. Após um aumento repentino de viscosidade durante a reação, todo o meio reacional foi colocado sobre uma superfície de vidro e espalhado rapidamente com o auxílio de um pincel (previamente limpo em acetona). Em seguida esta superfície de vidro foi colocada dentro de um dessecador

Tabela 1. Solventes empregados e respectivos parâmetros de solubilidade $\delta\left(\mathrm{cal}_{\mathrm{cm}} \mathrm{cm}^{-3}\right.$.

\begin{tabular}{lc}
\hline \multicolumn{1}{c}{ Solvente } & $\delta\left(\mathbf{c a l}^{\left.-\mathbf{c m}^{-3}\right)^{1 / 2}}\right.$ \\
\hline Éter etílico & 7,4 \\
Acetato de etila & 9,05 \\
Benzeno & 9,2 \\
Clorofórmio & 9,3 \\
Acetona & 9,9 \\
Etanol & 26,2 \\
Água & 23,4 \\
\hline
\end{tabular}

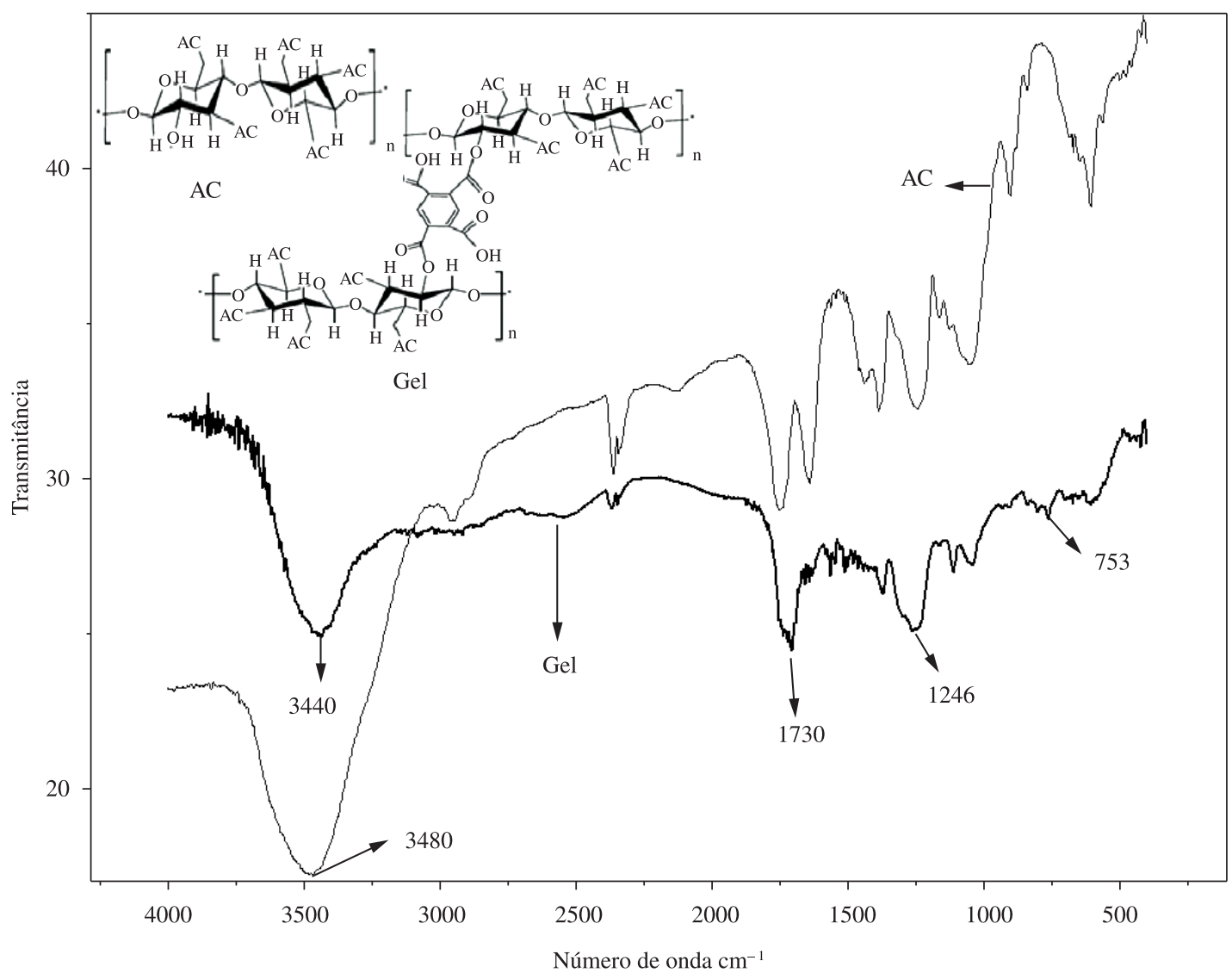

Figura 2. Espectros de FTIR do AC indentificada com a sigla AC e do gel GR31 com a sigla GEL. Na parte superior da figura temos as estruturas químicas do $\mathrm{AC}$ e do gel. 
em temperatura ambiente, onde permaneceu por 15 dias. Após a secagem, a superfície de vidro com o filme foi mergulhada em água destilada para o filme se desprender. Os filmes de AC foram secos em estufa com temperatura de $40{ }^{\circ} \mathrm{C}$ durante 24 horas e em seguida armazenado em dessecador. Posteriormente os filmes de géis foram mergulhados em etanol a $80 \%$ durante 14 dias e 10 dias em água destilada. Após a lavagem dos filmes, os mesmos foram secos em estufa a $40{ }^{\circ} \mathrm{C}$ durante 24 horas e armazenados em dessecador. $\mathrm{O}$ método foi formulado com base na literatura ${ }^{[10]}$.

\section{Resultados e Discussões}

O surgimento de novas bandas de FTIR nos géis (Figura 2) é a evidência da formação de um novo material. O típico espectro do gel mostrado na figura revela que o produto é composto de uma rede polimérica formada por novas ligações covalentes e com características de formação de ligações pós-esterificação e inclusão de aromáticos na estrutura. No espectro de FTIR também não aparecem as bandas de deformação axial de N-H de sais de amina terciária em $2680 \mathrm{~cm}^{-1}$. Esse total desaparecimento é uma evidência da eficiência do processo de lavagem, pois, foi possível remover toda a trietilamina que foi usada como catalisador na síntese.

As principais diferenças incluem as vibrações angulares fora do plano das ligações $\mathrm{C}-\mathrm{H}$ do anel a $753 \mathrm{~cm}^{-1}$ e a vibração de deformação axial de C-O em ésteres de ácidos aromáticos a $1246 \mathrm{~cm}^{-1}$. A $1730 \mathrm{~cm}^{-1}$ pode ser observada a mudança ocorrida na banda de absorção referente à carbonila, decorrente da introdução de outros ésteres na estrutura do material. Esta mudança foi observada também por Oliveira (2008, p. 54) na literatura já apresentada ${ }^{[1]}$, que

Tabela 2. Tabela de valores obtidos para a determinação de Mc, com a aplicação da teoria de Flory-Rehner.

\begin{tabular}{|c|c|c|c|c|}
\hline \multicolumn{5}{|c|}{ Dados obtidos através da teoria de Flory-Rehner } \\
\hline Gel & GR31 & GR11 & GR12 & GR13 \\
\hline Porcentagem de absorção no equilíbrio & 67,89 & 201,79 & 469,85 & 831,20 \\
\hline Coeficiente de intumescimento máximo, $\mathrm{Q}_{\mathrm{Max}}\left(\mathrm{cm}^{3} \cdot \mathrm{g}^{-1}\right)$ & 0,86 & 2,55 & 3,71 & 9,13 \\
\hline Volume reduzido, $\mathrm{V}_{\mathrm{r}}$ & 0,48 & 0,33 & 0,2136 & 0,1655 \\
\hline Densidade do gel, $\rho_{2}\left(\mathrm{gL} . \mathrm{cm}^{-3}\right)$ & 1,2800 & 1,1500 & 1,2716 & 1,2268 \\
\hline Parâmetro de solubilidade do gel, $\delta_{2}\left(\mathrm{cal} . \mathrm{cm}^{-3}\right)^{1 / 2}$ & 9,9 & 9,9 & 9,9 & 9,3 \\
\hline Parâmetro de interação polímero-solvente, $\chi$ & 0,34 & 0,34 & 0,34 & 0,34 \\
\hline Densidade de ligações cruzadas, $v\left(\mathrm{~g} . \mathrm{cm}^{-3}\right)$ & $1,867 \times 10^{-3}$ & $7,497 \times 10^{-4}$ & $2,425 \times 10^{-4}$ & $1,314 \times 10^{-4}$ \\
\hline Massa molar média entre pontos de entrecruzamento, $\mathrm{Mc}$ & 685 & 1534 & 5244 & 9336 \\
\hline № médio de unidades repetitivas entre pontos de entrecruzamento. & 1,2 & 2,9 & 9,8 & 17,5 \\
\hline
\end{tabular}

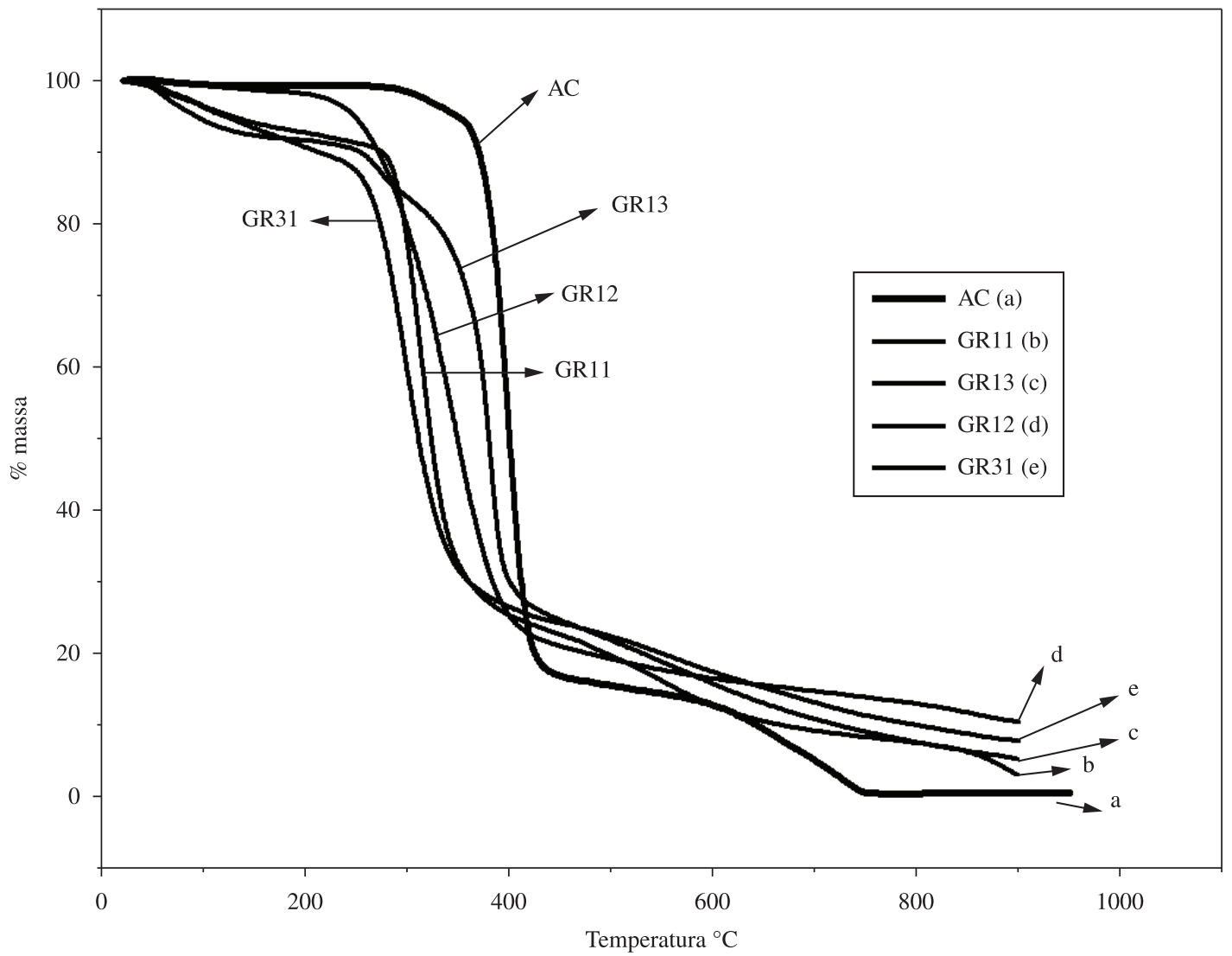

Figura 3. Curvas de TGA para o AC. As curvas dos géis e do acetato de celulose (AC) estão identificadas com as letras de a até e. Também estão indicados com as setas. 
é atribuída ao alargamento/desdobramento da banda de carbonila devido à incorporação de outros ésteres na estrutura, além de carbonila de cetona e ácido carboxílico presentes na estrutura dos agentes de entrecruzamento. Outro fato importante são as mudanças nas bandas de grupos $\mathrm{OH}$. No $\mathrm{AC}$, a banda de absorção ocorre em $3480 \mathrm{~cm}^{-1}$, típicas de hidroxilas alifáticas. No gel, os grupos $\mathrm{OH}$ são de origem, em grande parte, dos grupos ácidos carboxílicos formados após a reticulação das cadeias poliméricas do AC. Nesse caso, a absorção dessas hidroxilas ocorre em $3440 \mathrm{~cm}^{-1}$ com típico alargamento previsto para ácidos carboxílicos .

As Figuras 3 e 4 mostram as curvas de TGA e DTG para o AC e dos géis. A partir das curvas de TGA e suas respectivas curvas da primeira derivada, pôde-se concluir que o entrecruzamento das cadeias de AC pelo PMDA leva a uma redução na temperatura de degradação em todas as amostras com diferentes graus de entrecruzamento (as temperaturas de degradação estão indicadas na Figura 3).

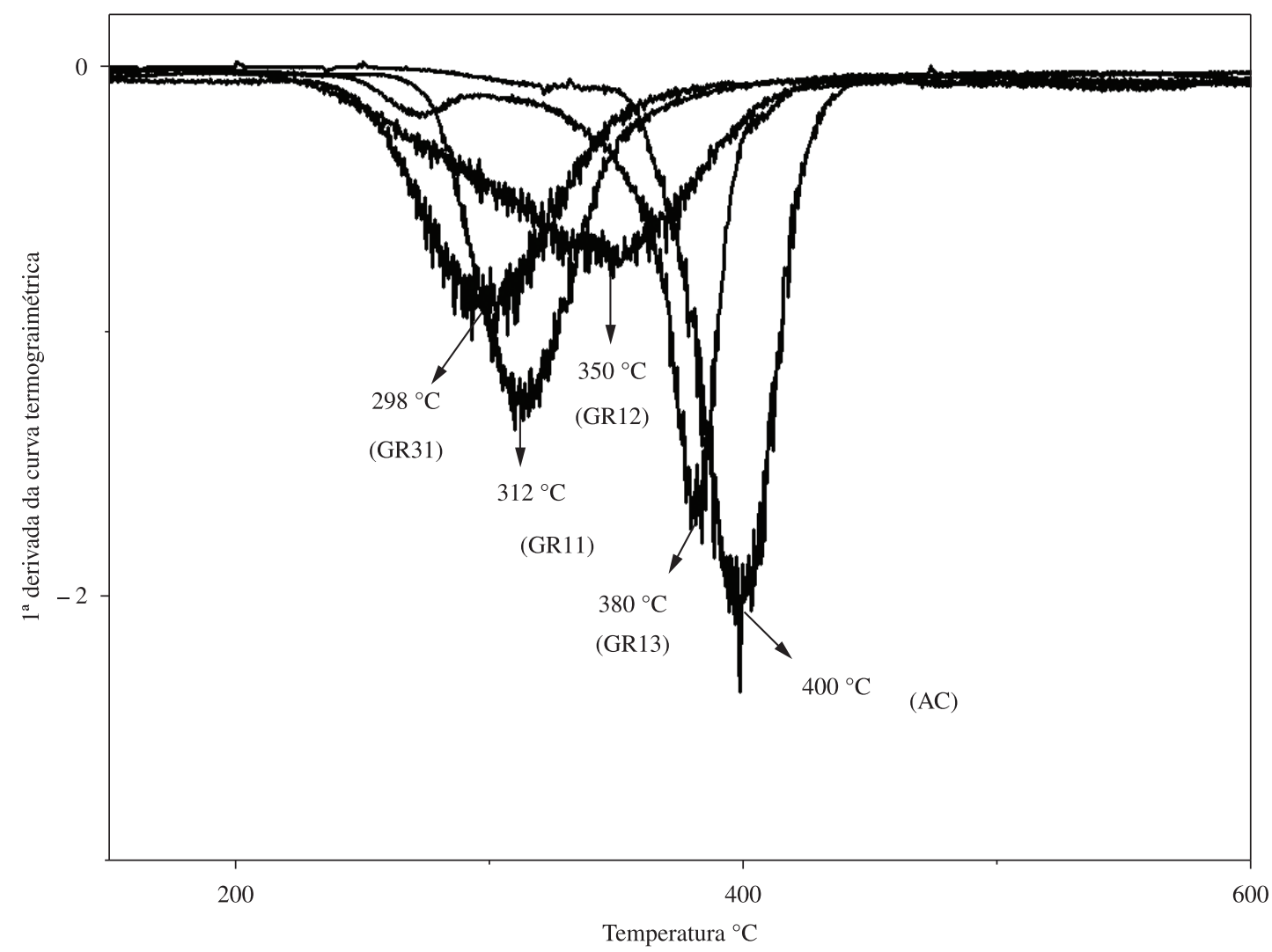

Figura 4. Curvas de DTG para o AC e géis. A curva de cada gel está identificada com uma seta e a sigla do gel entre parênteses.
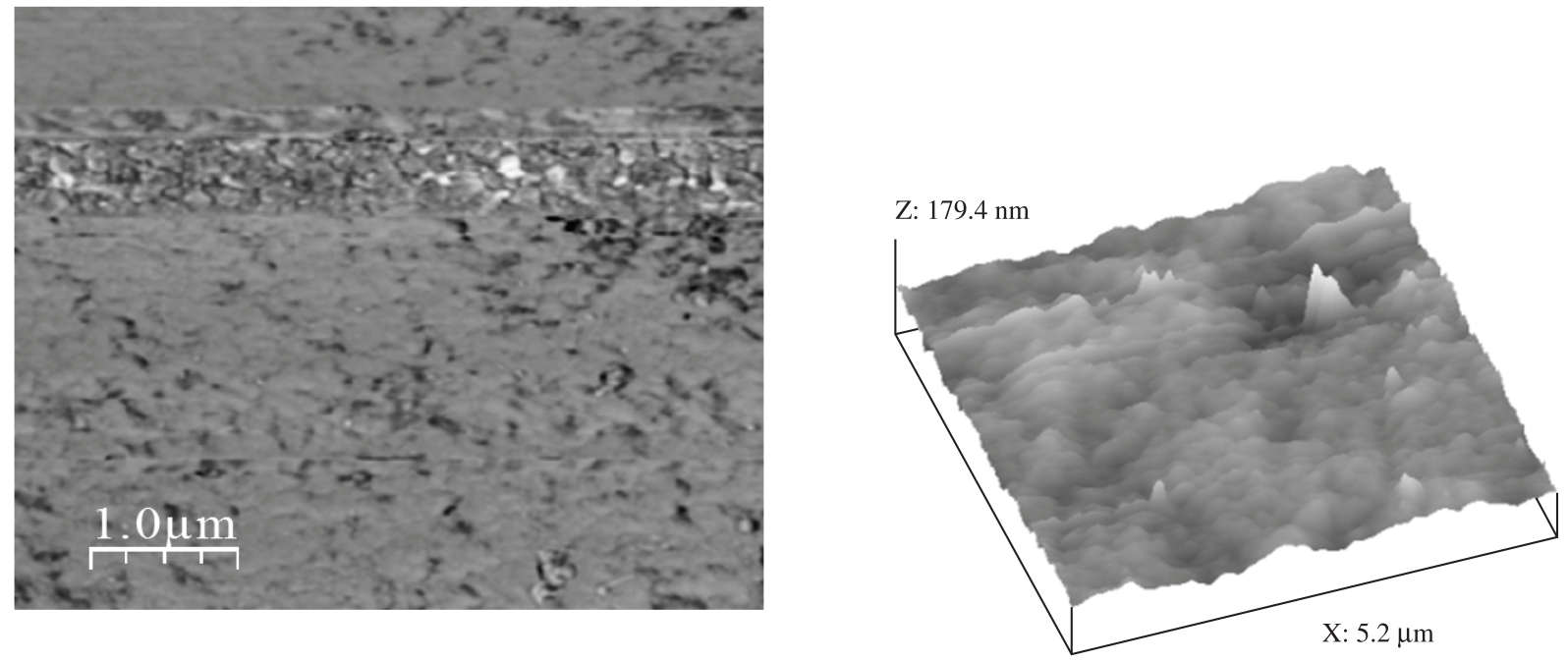

Figura 5. Micrografia de AFM do AC em 2D e 3D. 


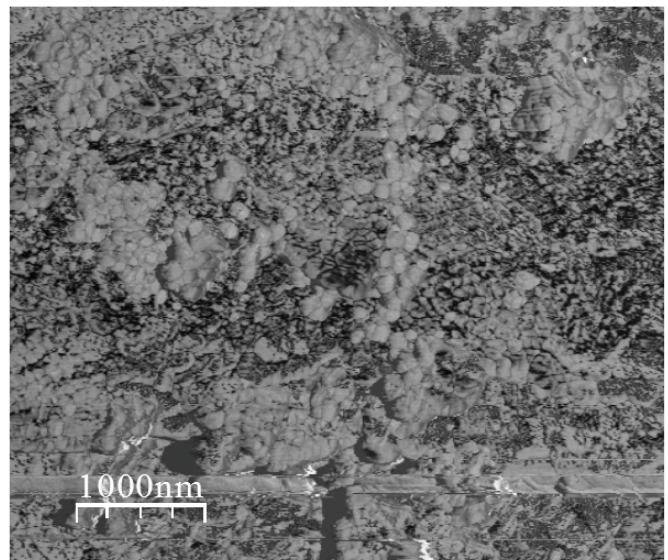

Figura 6. Micrografia de AFM do GR31 em 2D e 3D.

As ligações ésteres formadas no processo de gelificação são menos resistentes e são quebradas mais facilmente via degradação térmica. Isso está de acordo com a densidade de ligações cruzadas (Tabela 2). Um dado também bastante importante, calculada através da teoria de Flory-Rehner, é o número médio de unidades repetitivas entre os pontos de entrecruzamento (Mc). Com esses dados foi verificado que apenas $33 \%$ em quantidade de matéria do agente reticulador, o PMDA, reagiram com os grupos $\mathrm{OH}$ das cadeias poliméricas do AC para formar as ligações cruzadas. $\mathrm{O}$ valor de $33 \%$ foi obtido considerando-se os dados da Tabela 1 que mostram que apenas $1 / 3$ dos grupos $\mathrm{OH}$ livres reagiram com o PMDA. Esse importante resultado observado nos três géis com diferentes condições de entrecruzamento, sugere a presença de um equilíbrio químico nas reações de síntese. Para investigar a presença de equilíbrio químico durante a reação de síntese, foi feita uma síntese com excesso de PMDA para deslocar a reação no sentido de formação do produto, ou seja, a reação direta.

O GR31 teve densidade de ligações cruzadas muito superior aos outros hidrogéis, e consequientemente menor valor de $\mathrm{Mc}$ (Tabela 2). Também é possível verificar que o número médio de unidades repetitivas entre pontos de entrecruzamento foi muito próximo de 1 (um), ou seja, aproximadamente $100 \%$ dos grupos $\mathrm{OH}$ das cadeias poliméricas reagiram com o agente de entrecruzamento PMDA. Esse resultado comprovou o deslocamento da reação no sentido direto pelo emprego de excesso de agente de reticulação e proporcionou a formação de um material altamente entrecruzado.

As Figuras 5 e 6 mostram as imagens da superfície do AC e do gel GR31 2D e 3D com área de $5 \mu \mathrm{m}$, respectivamente. Os resultados de microscopia de força atômica mostram as modificações superficiais ocorridas após as reações de entrecruzamento.

A superfície do AC apresentou uma topografia diferenciada quando comparada com o GR31. A inclusão de grupos aromáticos volumosos no gel e a formação de um polímero termorrígido são fatos importantes para a diferenciação de topografias. Pode ser notada uma ausência de regularidade no GR31 em função da inclusão aleatória de grupos aromáticos em toda extensão das cadeias. A topografia relativamente regular da superfície do filme de AC por AFM corrobora com resultados já apresentados na literatura ${ }^{[10]}$.

\section{Conclusões}

O método de determinação da densidade de ligações cruzadas através da teoria de Flory-Rehner mostrou-se eficiente na determinação de ligações cruzadas nos hidrogéis. $\mathrm{O}$ aumento da densidade de ligações cruzadas seguiu a proporcionalidade esperada

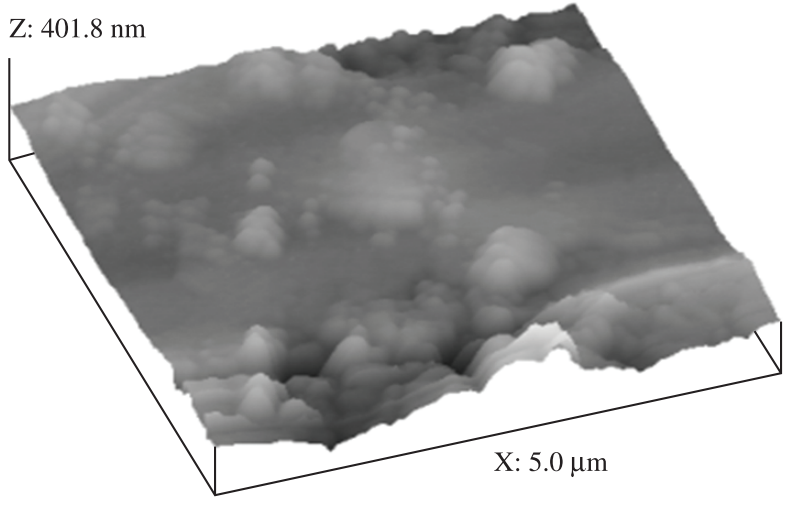

de acordo com o aumento do teor de agente de entrecruzamento utilizado na síntese. Foi possível obter géis com diferentes capacidades de intumescimento e com considerável potencial de aplicação desses materiais como absorventes. Os géis estudados neste trabalho oferecem grandes vantagens: a síntese é realizada em meio homogêneo garantindo melhor eficiência na reação, os géis são derivados de celulose que é um polímero de fontes renováveis e possuem custo relativamente baixo.

\section{Referências Bibliográficas}

1. Oliveira, V. - "Síntese e Caracterização de Géis de Acetato de Celulose Utilizando o Dianidrido do ácido 1,2,4,5 Benzenotetracarboxílico $e$ o Dianidrido da 3,3',4,4'Benzofenona Tetracarboxílico como agente Reticulante”, Dissertação de Mestrado, Universidade Federal de Ouro Preto, Brasil (2008).

2. Freire, C. S. R.; Silvestre, A. J. D.; Pascoal Neto, C. \& Rocha, R. M. A. - Cellulose, 12, p.449 (2005). http://dx.doi.org/10.1007/s10570005-2203-2

3. Samios, E.; Dart, R. K. \& Dawkins, J. V. - Polymer, 38, p.3045 (1997). http://dx.doi.org/10.1016/S0032-3861(96)00868-3

4. Senna, A. - "Géis de Acetato de celulose reticulados: Síntese, Caracterização e Estudos de Adsorção de Íons Cu II”, Dissertação de Mestrado, Universidade Federal de São Carlos, Brasil (2011).

5. Yonghao, A.; Francisco, J. S. \& Hanqing, J. - J. Mech. Phys. Solids, 58, p.2083 (2010). http://dx.doi.org/10.1016/j.jmps.2010.09.002

6. Akcelrud, L.; "Fundamentos da ciência dos polímeros", In: Ligações Cruzadas, cap.1, Leni Akcelrud, Manole, São Paulo (2007).

7. American Society for Testing and Materials - ASTM. - "ASTM D 871-96:Standard Tests for Celullose Acetate”, ASTM (2004).

8. American Society for Testing and Materials - ASTM. - "Annual Book of Standard", ASTM D 471, p.104 (1979).

9. American Society for Testing and Materials - ASTM. - "Annual Book of Standard", ASTM 1239-55, p.175 (1979).

10. Stamatialis, F. D.; Dias, R. C. \& Pinho, M. N. - J. Memb. Sci., 160, p.235 (1999). http://dx.doi.org/10.1016/S0376-7388(99)00089-7

Enviado: 05/05/11

Reenviado: $12 / 10 / 11$

Aceito: 10/02/12 